\title{
Experimental control of flower initiation in Weigela japonica
}

\author{
M. Bodson
}

Centre de Physiologie Végétale Appliquée (IRSIA), Université de Liègle, Institut de Botanique, B22, Sart Tilman, B-4000 Liège, Belgium

\section{Introduction}

Most of the experimental work on the mechanisms controlling flowering are reported for herbaceous annuals for which floral transition is under photoperiodic control. Experimentation with these species has emphasized the importance of the leaf system for the perception of the proper photoperiod and made clear that the leaf processes resulting in the synthesis of the flowering stimulus are a major control point of the floral transition (Zeevaart, 1976; Bernier, 1988).

Several characteristics are specific to the floral transition of woody perennials. For most woody species of the temperate zone: 1) flowers are initiated on resting axillary buds; 2) there is a long rest period between flower initiation and anthesis; 3 ) there is no direct control of flower initiation by the daylength, while vegetative growth may be under strong photoperiodic control (Nitsch, 1957); and 4) the floral response is localized to certain buds (Jackson and Sweet, 1972; Buban and Faust, 1982). The causes of this localization of the floral response are still largely unknown and may be related to physiological conditions internal to the bud (Romberger, 1963; Crabbe, 1984). One may thus suspect that the floral transition of woody species is controlled by specific mechanisms not found in photoperiodic annuals. A study has been started with Weigela japonica, a woody ornamental, to consider some aspects of this question. Results are reported on the effect of a pruning treatment on the floral response of resting axillary buds. Two points were investigated: 1) the floral response with regard to the age of the buds located at a similar node position; and 2) the floral response at a single time of pruning applied at different node positions on the same axis.

\section{Materials and Methods}

Plants were propagated by cuttings. The rooted cuttings were first potted in leaf mould in $7-\mathrm{cm}$ clay pots. After $3 \mathrm{wk}$, they were transplanted into peat moss $\left(\mathrm{TKS}_{2}\right.$, Oldenburg, Germany) and pinched so as to keep 2 leaf pairs and their respective axillary buds. Such a plant will de- 
velop 4 axillary shoots. The zero time was arbitrarly fixed at the time of pinching. The plants were kept in 16-h LD, under fluorescent tubes (cool white, $4300^{\circ} \mathrm{K}, \mathrm{ACEC}$, Charleroi, Belgium), at a constant temperature of $20^{\circ} \mathrm{C}$ and relative humidity of $60 \%$. The light flux at the top of the canopy was $250 \mu \mathrm{E} \cdot \mathrm{m}^{-2} \cdot \mathrm{s}^{-1}$. Under these conditions, all the axillary buds from intact plants remained vegetative for up to $150 \mathrm{~d}$. Results reported here concern only those buds located at the node just below the pruning zone.

\section{Results}

In the first experiment, ramifications of different ages were pruned so as to keep 3 nodes. For an early pruning, realized after $40 \mathrm{~d}$ of growth, all buds developed as leafy shoots (Table I). When 90-d old ramifications were pruned, $80 \%$ of the buds developed as reproductive axes and the floral response decreased for later pruning times.

In the second experiment, the pruning treatments were applied to $90-\mathrm{d}$ old shoots and carried out so as to keep a variable number of nodes (from 1 to 4 ). The type of development of the axillary buds depended upon their position on the shoot (Table II). The buds located at the base of the ramification developed essen-

Table I. Effect of a pruning treatment as a function of the age of the ramification on the development of the resting axillary buds.

\begin{tabular}{lll}
\hline $\begin{array}{l}\text { Age of ramification } \\
\text { at time of pruning } \\
\text { (d) }\end{array}$ & Percent & \\
\cline { 2 - 3 } & teafy shoots & $\begin{array}{c}\text { reproductive } \\
\text { axes }\end{array}$ \\
\hline 40 & 100 & 0 \\
90 & 20 & 80 \\
110 & 40 & 60 \\
\hline
\end{tabular}

The pruning treatment was carried out so as to keep 3 nodes on each ramification.
Table II. Effect of the position of a pruning treatment on the development of the resting axillary buds.

\begin{tabular}{|c|c|c|}
\hline \multirow{2}{*}{$\begin{array}{l}\text { Position of pruning } \\
\text { (node number } \\
\text { from the base) }\end{array}$} & \multicolumn{2}{|l|}{ Percent } \\
\hline & leafy shoots & $\begin{array}{l}\text { reproductive } \\
\text { axes }\end{array}$ \\
\hline 1 & 88 & 12 \\
\hline 2 & 44 & 56 \\
\hline 3 & 22 & 78 \\
\hline 4 & 40 & 60 \\
\hline
\end{tabular}

tially as leafy shoots and the percentage of buds developing as reproductive axes increased with the position of the buds. The optimum was observed for buds located at the axil of node 3 .

\section{Conclusions}

These results show that: 1) at a specific time, all the axillary buds located along the ramification did not have a similar capacity to initiate flowers in response to a pruning treatment; and 2) there was an optima! timing for buds at a specific location on the ramification to respond to a treatment promoting flowering. These observations suggest that the control of flowering is at least partially located within the bud. This control could be related to morphological or biochemical properties of certain components of the bud specific to its physiological age and/or linked to the relation of the bud to the other growth centers of the plant.

An anatomical description of the bud with regard to its organogenetic activity is presently under investigation to detect and localize within the bud the histological modifications specifically involved in the floral transition. 


\section{References}

Bernier G. (1988) The control of floral evocation and morphogenesis. Annu. Rev. Plant Physiol. $39,175-219$

Buban T. \& Faust M. (1982) Flower bud induction in apple trees: internal control and differentiation. Hortic. Rev. 4, 174-203

Crabbe J.J. (1984) Vegetative vigor control over location and fate of flower buds in fruit trees. Acta Hortic. 149, 55-63
Jackson D.J. \& Sweet G.B. (1972) Flower initiation in temperate woody plants. Hortic. Abstr. 42, 9-24

Nitsch J.P. (1957) Photoperiodism in woody plants. Proc. Am. Soc. Hortic. Sci. 70, 526-544

Romberger J.A. (1963) Meristems, growth and development in woody plants. US Department of Agriculture, Technical Bull. no. 1293, pp. 214

Zeevaart J.A.D. (1976) Physiology of flower formation. Annu. Rev. Plant Physiol. 27, 321-348 